Research Paper

\title{
Effects of Postoperative Radiotherapy in Early Breast Cancer Patients Older than 75 Years: A Propensity-Matched Analysis
}

\author{
Linghui Zhou ${ }^{1,2^{*}}$, Pengtao Yang2 ${ }^{2 *}$, Yi Zheng1 ${ }^{*}$, Tian Tian1,2, Cong Dai1, Meng Wang2, Shuai Lin², Yujiao \\ Deng ${ }^{1,2}$, Qian Hao ${ }^{1,2}$, Zhen Zhai ${ }^{1,2}$, Hongtao Li $^{\circledR}$ and Zhijun Dai ${ }^{1 凶}$ \\ 1. Department of Breast Surgery, The First Affiliated Hospital, School of Medicine, Zhejiang University, Hangzhou 310003, Zhejiang, China. \\ 2. Department of Oncology, The 2nd Affiliated Hospital of Xi' an Jiaotong University, Xi'an 710004, Shaanxi, China. \\ 3. Department of Breast Head and Neck surgery, The 3rd Affiliated Teaching Hospital of Xinjiang Medical University (Affiliated Tumor Hospital), Urumqi \\ 830000, Xinjiang, China. \\ * LH Z, PT Y and Y Z contributed equally to this work.
}

$\square$ Corresponding authors: Zhijun Dai, Department of Breast Surgery, First Affiliated Hospital, Zhejiang University School of Medicine, Hangzhou 310003, China (E-Mail: dzj0911@126.com), or Hongtao Li, Department of Breast Head and Neck surgery, The 3rd Affiliated Teaching Hospital of Xinjiang Medical University (Affiliated Tumor Hospital), Urumqi, 830000, China (E-Mail: 1ht4656@163.com).

(1) The author(s). This is an open access article distributed under the terms of the Creative Commons Attribution License (https://creativecommons.org/licenses/by/4.0/). See http://ivyspring.com/terms for full terms and conditions.

Received: 2019.03.25; Accepted: 2019.08.06; Published: 2019.10.17

\begin{abstract}
Background: Currently, there is still some controversy regarding whether early breast cancer patients with a tumor size of $\leq 5 \mathrm{~cm}$ and $1-3$ positive lymph nodes should undergo postoperative radiotherapy (PRT).

Materials and Methods: We obtained data from the Surveillance, Epidemiology, and End Results (SEER) 18 database. Then, we conducted propensity score matching (PSM), according to the radiotherapy record. The Kaplan-Meier and Cox regression analysis were conducted to explore prognostic factors in breast cancer.

Results: A total of 6,777 patients aged 75+ years old were eligible and 2,361 patients were included after PSM. We found PRT could improve patient overall survival $(\mathrm{OS})(P=0.01$, hazard ratio $[\mathrm{HR}]=$ $0.88,95 \%$ confidence interval $[\mathrm{Cl}], 0.80-0.97)$. Subgroup analysis revealed PRT could improve OS in patients with hormone receptor positive $(\mathrm{HR}+)(P=0.001, \mathrm{HR}=0.84,95 \% \mathrm{Cl}, 0.76-0.94)$ or white patients $(P=0.004, \mathrm{HR}=0.86,95 \% \mathrm{Cl}, 0.77-0.95)$.

Conclusions: PRT may benefit for elderly women with early breast cancer, especially in HR+ patients or white patients. These findings may inform future optimized options whether elderly female patients with early breast cancer should undergo postoperative radiotherapy.
\end{abstract}

Key words: postoperative radiotherapy, early breast cancer, seer database, propensity score matching; prognosis

\section{Introduction}

Reportedly, breast cancer is the most commonly diagnosed cancer and accounts for $30 \%$ of new cancers diagnosed amongst American females. In 2017 , a total of 252,710 people were newly diagnosed with breast cancer and 40,610 females died of breast cancer [1]. Due to increased life expectancy and early breast cancer screening programs, there is a rapid increase in the incidence of breast cancer in elderly patients in both developed and developing countries [2]. For example, in the United States, elderly patients $\geq 60$ years old account for more than $40 \%$ of deaths due to breast cancer [1]. It is well known that surgery and radiotherapy are the main treatment strategies for breast cancer in regional lymph nodes. The purpose of surgery is to remove the tumor and regional lymph nodes. However, surgery cannot guarantee complete 
removal of cancer cells from the skin, chest wall, and lymph nodes, which might increase the risk of relapse. A meta-analysis suggested radiotherapy could reduce the 10-year risk of any first recurrence and the 15-year risk of breast cancer death [3]. The role of PRT is still controversial when the tumor size is $\leq 5 \mathrm{~cm}$ and the number of positive lymph nodes is between one and three [4-6]. Certain studies suggest that radiotherapy may impair the quality of life in elderly patients $[7,8]$. A trial of PRT in minimum-risk elderly patients showed that most elderly breast cancer patients can tolerate PRT well without impairing their overall health-related quality of life [9].

Radiotherapy exerts cytotoxic effects by generating free radicals in the target tissue. These free radicals are the source of reactive oxygen species and reactive nitrogen species that produce DNA damage by forming single stranded DNA breaks (SSB) and double stranded DNA breaks (DSB) [10]. Due to the specificity of breast cancer cells, differences in chemotherapy and endocrine therapy between different subtypes have been confirmed [11]. Similarly, Mao et al found that sensitivity to radiotherapy is different among breast cancer subtypes [12]. In vitro cell experiments also show that breast cancer cells of different subtypes have different sensitivity to ionizing radiation [10].

\section{Materials and Methods}

\section{Patients}

We obtained patient data from SEER 18 Regs Custom Data (with additional treatment fields), Nov 2017 Sub (1973-2015 varying), using SEER*Stat, version 8.3.5. A total of 6,777 patients were eligible and 2,361 patients were included after PSM. The flow chart for selecting research samples is shown in the Figure 1. The following variables were used in the analysis: age, race, marital status, months of survival, vital status records, cause-specific death classification, AJCC T, number of positive regional nodes, ER, PR, grade, laterality, radiation record, and sugery.

\section{Statistical analyses}

In order to improve the evidence level of the test and control for known variables except for PRT on the experimental, 1:2 patient pairing with a caliper size of 0.1 was performed by PSM. Patients aged 75 years who had undergone surgery were divided into two groups according to whether or not PRT was given. We used frequencies and proportions for categorical variables to describe the characteristics of patients and compared the difference of two groups using the chi-square $\left(X^{2}\right)$ test. To evaluate the effect of radiotherapy, Kaplan-Meier analysis and log-rank test were conducted. A Cox proportional hazards

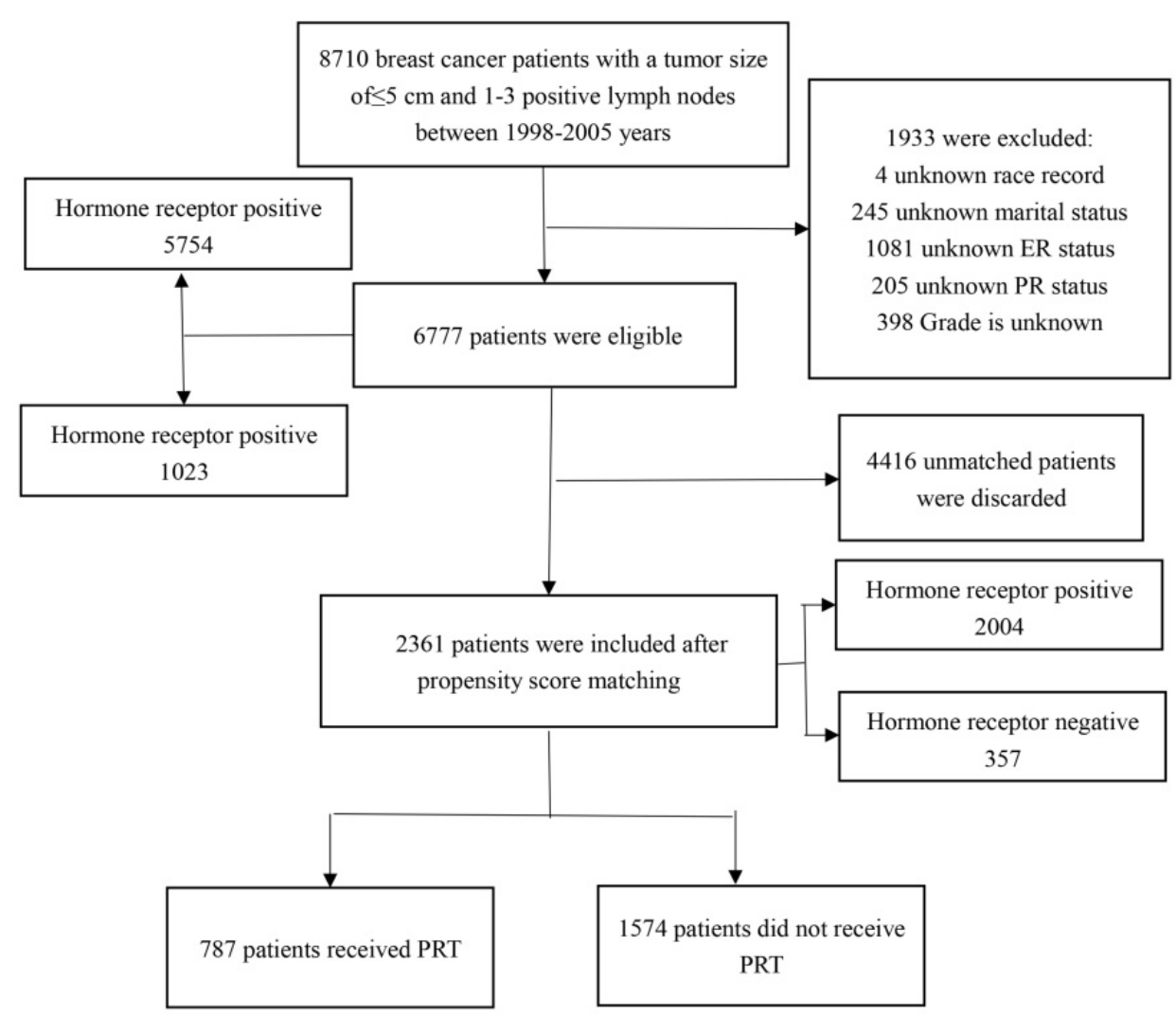

Figure 1. Flow chart of study patients' enrollment. PRT: postoperative radiotherapy. 
regression model was conducted to predict independent risk factors for all-cause and breast cancer-specific death. All statistical tests were two-sided, with statistical significance evaluated at the 0.05 alevel. All calculations were performed by $\mathrm{R}$ software (version 3.5.1).

Table 1. Baseline Demographic and Tumor Characteristics of Unmatched Patients Stratified by Radiation Status

\begin{tabular}{|c|c|c|c|c|}
\hline \multirow[t]{2}{*}{ Characteristic } & \multirow[t]{2}{*}{ Total (6777) } & \multicolumn{2}{|l|}{ Receipt of PRT } & \multirow[t]{2}{*}{ P Value } \\
\hline & & No $(4296 ; 63.39)$ & Yes $(2481 ; 36.61)$ & \\
\hline Age & & & & $<0.001^{*}$ \\
\hline $75-79$ years & 3488 & $2025(47.43)$ & $1463(58.97)$ & \\
\hline $80-84$ years & 2186 & $1403(32.86)$ & $783(31.56)$ & \\
\hline $85+$ years & 1103 & $868(20.33)$ & $235(9.47)$ & \\
\hline Race & & & & 0.505 \\
\hline Black & 458 & $300(7.03)$ & $158(6.37)$ & \\
\hline Other & 261 & $170(3.98)$ & $91(3.67)$ & \\
\hline White & 6058 & $3826(89.62)$ & $2232(89.96)$ & \\
\hline Marital Status & & & & $<0.001^{*}$ \\
\hline Married & 2427 & $1431(33.52)$ & $996(40.15)$ & \\
\hline Single (never married) & 3883 & $2553(59.80)$ & $1330(53.61)$ & \\
\hline $\begin{array}{l}\text { Widowed/Divorced/ } \\
\text { Separated }\end{array}$ & 467 & $312(7.31)$ & $155(6.25)$ & \\
\hline AJCC T & & & & $<0.001^{*}$ \\
\hline $\mathrm{T} 1$ & 3496 & $1955(45.80)$ & $1541(62.11)$ & \\
\hline $\mathrm{T} 2$ & 3281 & $2341(54.84)$ & $940(37.89)$ & \\
\hline Lymph node & & & & $<0.001^{*}$ \\
\hline 1 & 4199 & $2587(60.60)$ & $1612(64.97)$ & \\
\hline 2 & 1679 & $1110(26.00)$ & $569(22.93)$ & \\
\hline 3 & 899 & $599(14.03)$ & $300(12.09)$ & \\
\hline ER & & & & $<0.001^{*}$ \\
\hline Negative & 1080 & $754(17.66)$ & $326(13.14)$ & \\
\hline Positive & 4797 & $3542(82.97)$ & $1255(50.58)$ & \\
\hline PR & & & & $<0.001^{*}$ \\
\hline Negative & 2095 & $1406(32.94)$ & $689(27.77)$ & \\
\hline Positive & 4682 & $2890(67.70)$ & $1792(72.23)$ & \\
\hline Grade & & & & $<0.001^{*}$ \\
\hline $\mathrm{I}+\mathrm{II}$ & 4428 & $2738(64.14)$ & $1690(68.12)$ & \\
\hline III+IV & 2349 & $1558(36.50)$ & $791(31.88)$ & \\
\hline Laterality & & & & 0.746 \\
\hline Left & 3513 & $2220(52.00)$ & $1293(52.12)$ & \\
\hline Right & 3264 & $2076(48.63)$ & $1188(47.88)$ & \\
\hline Surgery & & & & $<0.001^{*}$ \\
\hline Lumpectomy & 2705 & $674(15.7)$ & 2031 (81.9) & \\
\hline Mastectomy & 4072 & $3622(84.3)$ & $450(18.1)$ & \\
\hline
\end{tabular}

${ }^{*} \mathrm{P} \leq 0.05$ indicates statistical significance.

\section{Results}

\section{Patient demographics}

A total of 6,777 patients were identified from SEER 18 Regs Custom Data (with additional treatment fields), Nov 2017 Sub (1973-2015 varying), according to the above-mentioned inclusion criteria. The median survival time for all patients was 89 months (range, 0 - 215 months). A total of 5316 (78.44\%) patients died of all causes and 1147 (16.92\%) died of breast cancer. Of the included patients, 2481 (36.61\%) patients received PRT and 4296 (63.39\%) did not receive PRT. There were significant differences in age $(P<0.001)$, marital status $(P<0.001)$, lymph node $(P<0.001)$, AJCC.T $(P<0.001)$, ER status $(P<0.001)$, PR status $(P<0.001)$, grade $(P<0.001)$, and surgery $(P$
$<0.001$ ) between the patients receiving PRT and the patients not receiving PRT. As for race $(P=0.505)$ and laterality $(P=0.746)$, no significant difference was found. The details are listed in Table 1.After PSM, all characteristics between the two groups were perfectly balanced. The details are listed in Supplemental Table S1.

\section{Prognostic value of PRT on OS}

The results of Kaplan-Meier method and log-rank test showed that PRT could improve patient OS before and after PSM (Figure 2). We conducted a univariate analysis and found that all the factors (except for laterality) for OS were significant, and then included all the factors into the multivariate Cox regression for analysis. The results of the Cox proportional hazards regression model showed that age, marital status, AJCC T, PR, grade, surgery and radiotherapy are independent risk factors for overall survival. Patients aged 80-84 years-old compared with those aged 75-79 years-old had an HR of 1.37 ( $P$ $<0.001,95 \% \mathrm{CI}, 1.24-1.52$ ); patients aged $\geq 85$ years-old compared with those aged 75-79 years-old had an HR of 2.19 ( $P<0.001,95 \%$ CI, $1.90-2.52)$. Compared with married patients, widowed/ divorced/separated patients had an HR of 1.27 ( $P$ $<0.001,95 \% \mathrm{CI}, 1.15-1.41$ ) and single people (never married) had an HR of 1.21 ( $P=0.033,95 \%$ CI, 1.02 1.44). Patients with $T 2$ stage compared with patients with T1 stage had an HR of $1.25(P<0.001,95 \%$ CI, 1.14 - 1.38). Compared with patients with one positive lymph node, patients with three positive lymph nodes had an HR of 1.19 ( $P=0.006,95 \% \mathrm{CI}, 1.05-1.35)$. PR+ patients had an HR of 0.83 (P =0.001, 95\% CI, 0.74 0.93) compared with PR- patients. Patients with grade III-IV compared with grade I-II breast cancer had an HR of $1.15(P<0.001,95 \% \mathrm{CI}, 1.07-1.24)$. The patients receiving PRT compared with those not receiving PRT had an HR of 0.88 ( $P=0.01,95 \% \mathrm{CI}, 0.80-0.97)$. The patients receiving mastectomy treatment compared with those receiving lumpectomy treatment had an HR of 1.13 ( $P=0.016,95 \%$ CI, $1.02-1.15)$. Details were shown in Table 2 and Figure 3.

\section{Subgroup analysis stratified by race and $H R$ status}

The results of Kaplan-Meier method and log-rank test revealed that $\mathrm{HR}+$ patients underwent PRT had a better OS (Figure 4, $P=0.0019$ ). As shown in Table 3, this was in accordance with the results of multivariate Cox analysis before $(P<0.001, \mathrm{HR}=0.80$, $95 \% \mathrm{CI}, 0.74-0.87)$ and after PSM $(P=0.001, \mathrm{HR}=$ $0.84,95 \% \mathrm{CI}, 0.76-0.94)$. However, the results of multivariate Cox analysis revealed no association between PRT and HR-patients $(P=0.62, \mathrm{HR}=1.05$, 
$95 \% \mathrm{CI}, 0.87-1.27)$. In addition, we found patients receiving PRT had a better and OS $(P=0.002)$ among white patients, compared with patients not receiving PRT. The results of multivariate analysis also showed

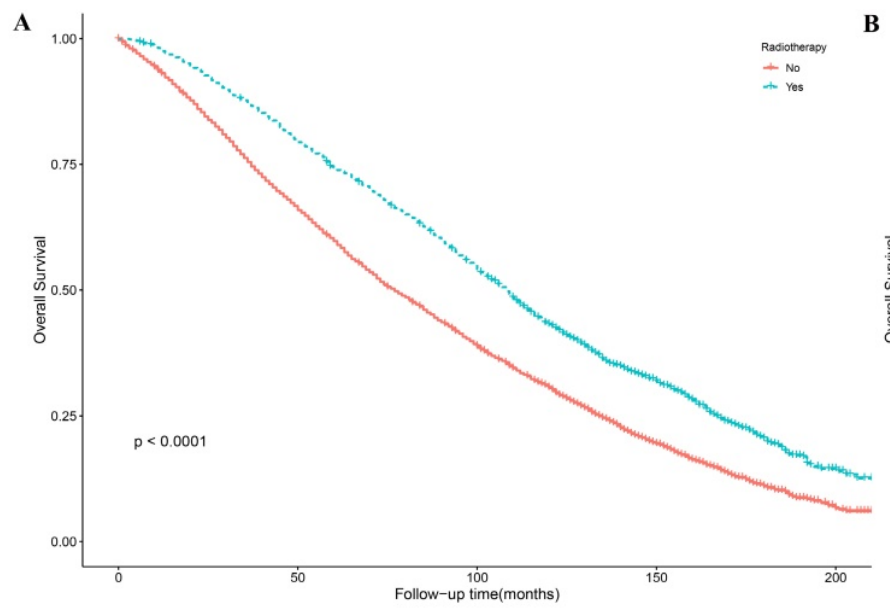

that patients receiving PRT had a better OS among white patients $(P=0.004, \mathrm{HR}=0.86,95 \% \mathrm{CI}, 0.77$ 0.95). Details were shown in Table 4.

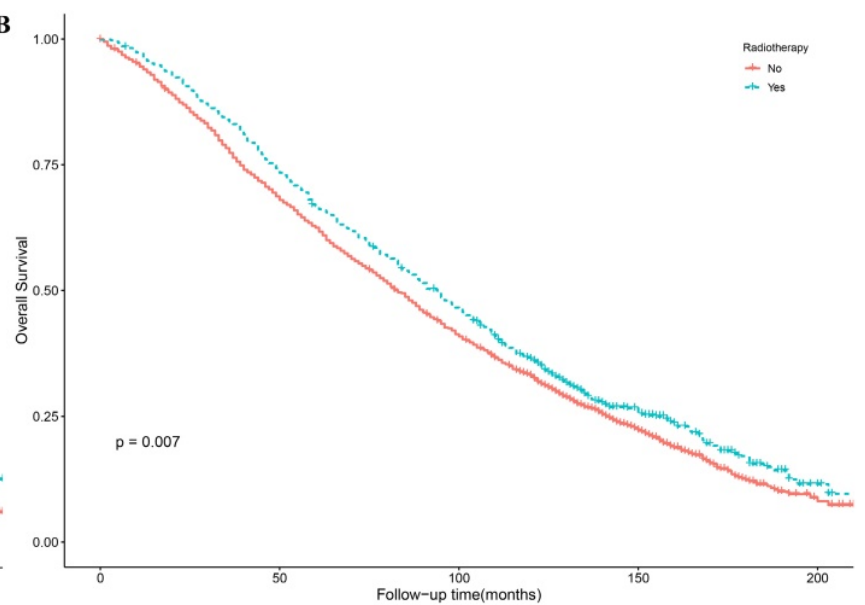

Figure 2. Kaplan-Meier survival curves in early breast cancer patients with age >= 75 Years for overall survival before (A) and after (B) PSM. PSM: propensity score matching.

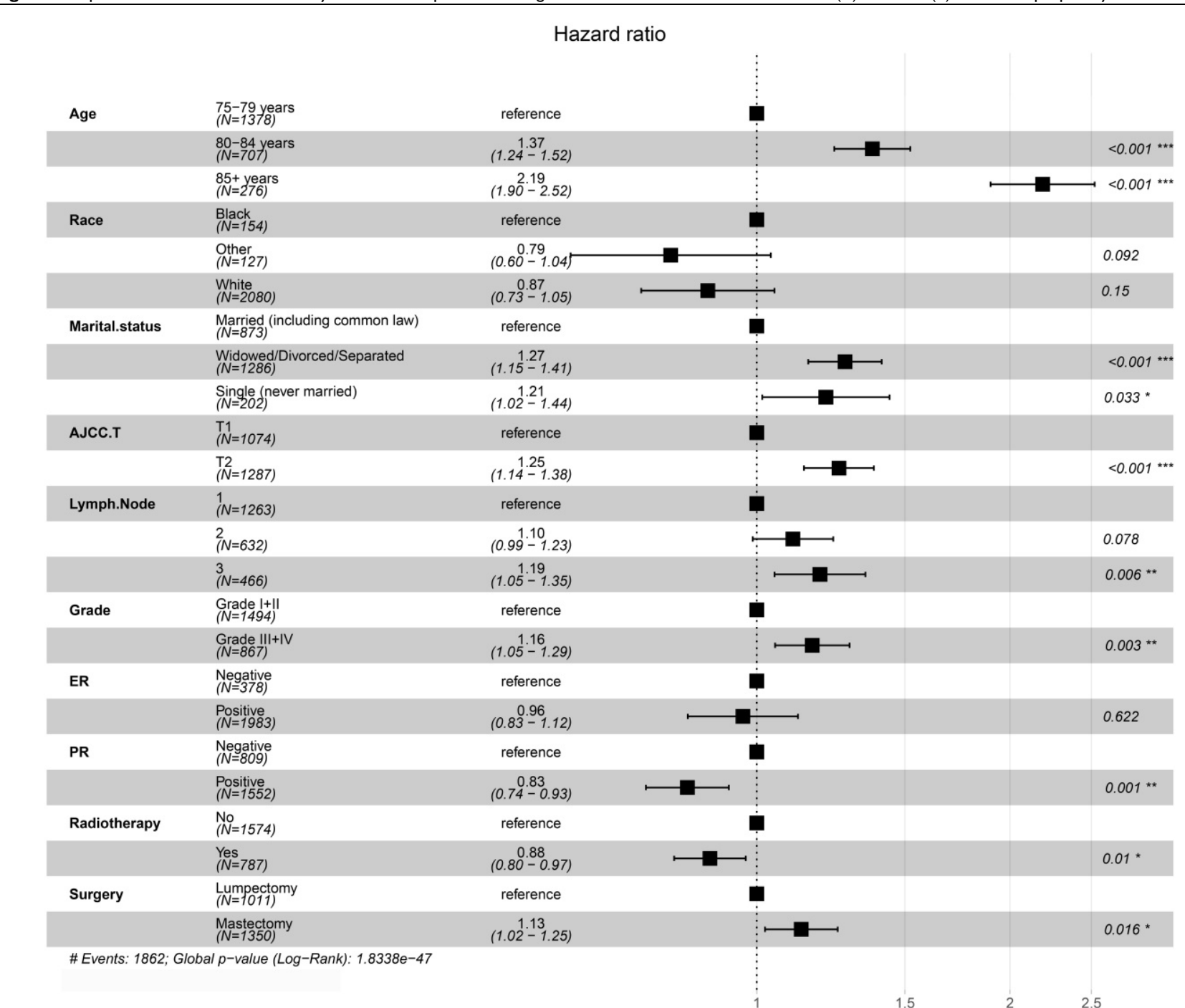

Figure 3. Forest plots of multivariate Cox regression analysis for overall survival in matched patients. 


\section{Sensitivity analysis}

To verify the stability of our results, we also conducted a multivariate Cox regression analysis of unmatched patients for OS. The results of multivariate Cox regression analysis of unmatched patients were basically consistent with those of matched patients. The details were listed in Supplemental Table S2.

\section{Discussion}

To our knowledge, this study is the first research to explore the role of elderly female breast cancer patients older than 75 years old with a tumor size of $\leq$ $5 \mathrm{~cm}$ and 1-3 positive lymph nodes, based on SEER database. We found that PRT may benefit for elderly women with early breast cancer, especially in HR+ patients or white patients.

Age was an important indicator for overall survival, and there was an imbalance in the age distribution of patients who received PRT $(9.47 \%$, $\geq 85$-years-old) and those who did not receive PRT $(20.33 \%, \geq 85$-years-old). The number of patients receiving radiation therapy decreased with age, which might be due to the lowering of expectations of survival for the elderly. However, there was no clear evidence that PRT was not beneficial to this population. We found an inverse association between the receipt of postoperative radiotherapy and age. Moreover, patients who received postoperative radiotherapy, on average, tended to have a higher OS. This is consistent with the research conducted by Ali et al [13]. As the average life expectancy in the United States continues to increase, the standard for "elderly" care may continue to rise. We chose 75 years old as the distinction for elderly patients compared to previous research using 70 years old and was consistent with the latest National Comprehensive Cancer Network $(\mathrm{NCCN})$ clinical practice guidelines [14].

Table 2. Analysis of Overall Survival in Matched Patients Stratified by Demographic Data and Radiation Treatment

\begin{tabular}{|c|c|c|c|c|c|c|c|}
\hline \multirow[t]{2}{*}{ Characteristic } & \multirow[t]{2}{*}{ Patients,n } & \multirow[t]{2}{*}{ Events,n } & \multirow[t]{2}{*}{ Rate, $\%$} & \multicolumn{2}{|c|}{ Univariate Analysis } & \multicolumn{2}{|c|}{ Multivariable Analysis } \\
\hline & & & & HR $(95 \%$ CI) & $P$ Value & HR $(95 \%$ CI) & $P^{a}$ Value \\
\hline \multicolumn{8}{|l|}{ Age } \\
\hline $75-79$ years & 1378 & 1012 & 73.44 & Ref & Ref & Ref & Ref \\
\hline $80-84$ years & 707 & 593 & 83.88 & $1.39(1.26-1.54)$ & $<0.001^{*}$ & $1.37(1.24-1.52)$ & $<0.001^{*}$ \\
\hline $85+$ years & 276 & 257 & 93.12 & $2.20(1.91-2.52)$ & $<0.001^{*}$ & $2.19(1.90-2.52)$ & $<0.001^{*}$ \\
\hline \multicolumn{8}{|l|}{ Race } \\
\hline Black & 154 & 126 & 81.82 & Ref & Ref & Ref & Ref \\
\hline Other & 127 & 91 & 71.65 & $0.75(0.57-0.99)$ & 0.039 & $0.79(0.60-1.04)$ & 0.092 \\
\hline White & 2080 & 1654 & 79.52 & $0.87(0.72-1.04)$ & 0.126 & $0.87(0.73-1.05)$ & 0.15 \\
\hline \multicolumn{8}{|l|}{ Marital Status } \\
\hline Married & 873 & 645 & 73.88 & Ref & Ref & Ref & Ref \\
\hline Widowed/Divorced/Separated & 1286 & 1055 & 82.04 & $1.40(1.27-1.55)$ & $<0.001^{*}$ & $1.27(1.15-1.41)$ & $<0.001^{*}$ \\
\hline Single (never married) & 202 & 162 & 80.20 & $1.28(1.08-1.52)$ & $0.005^{*}$ & $1.21(1.02-1.44)$ & $0.033^{*}$ \\
\hline \multicolumn{8}{|l|}{ AJCC T } \\
\hline $\mathrm{T} 1$ & 1074 & 802 & 74.67 & Ref & Ref & Ref & Ref \\
\hline $\mathrm{T} 2$ & 1287 & 1060 & 82.36 & $1.37(1.25-1.51)$ & $<0.001^{*}$ & $1.25(1.14-1.38)$ & $<0.001^{*}$ \\
\hline \multicolumn{8}{|l|}{ Lymph node } \\
\hline 1 & 1263 & 963 & 76.25 & Ref & Ref & Ref & Ref \\
\hline 2 & 632 & 508 & 80.38 & $1.17(1.05-1.30)$ & $0.005^{*}$ & $1.10(0.99-1.23)$ & 0.078 \\
\hline 3 & 466 & 391 & 83.91 & $0.36(1.21-1.53)$ & $<0.001^{*}$ & $1.19(1.05-1.35)$ & $0.006^{*}$ \\
\hline \multicolumn{8}{|l|}{ ER } \\
\hline Negative & 378 & 313 & 82.80 & Ref & Ref & Ref & Ref \\
\hline Positive & 1983 & 1549 & 78.11 & $0.76(0.67-0.86)$ & $<0.001^{*}$ & $0.96(0.83-1.12)$ & 0.622 \\
\hline \multicolumn{8}{|l|}{ PR } \\
\hline Negative & 809 & 671 & 82.94 & Ref & Ref & Ref & Ref \\
\hline Positive & 1552 & 1191 & 76.74 & $0.78(0.71-0.86)$ & $<0.001^{*}$ & $0.83(0.74-0.93)$ & $0.001^{*}$ \\
\hline \multicolumn{8}{|l|}{ Grade } \\
\hline I+II & 1494 & 1150 & 76.97 & Ref & Ref & Ref & Ref \\
\hline III+IV & 867 & 712 & 82.12 & $1.29(1.18-1.42)$ & $<0.001^{*}$ & $1.16(1.05-1.29)$ & $0.003^{*}$ \\
\hline \multicolumn{8}{|l|}{ Laterality } \\
\hline Left & 1188 & 942 & 79.29 & Ref & Ref & & \\
\hline Right & 1173 & 920 & 78.43 & $0.96(0.88-1.05)$ & 0.357 & & \\
\hline \multicolumn{8}{|l|}{ Surgery } \\
\hline Lumpectomy & 1011 & 768 & 75.96 & Ref & Ref & Ref & Ref \\
\hline Mastectomy & 1350 & 1094 & 81.04 & $1.16(1.06-1.27)$ & $0.001^{*}$ & $1.13(1.02-1.25)$ & $0.016^{*}$ \\
\hline \multicolumn{8}{|l|}{ Radiotherapy } \\
\hline No & 1574 & 1264 & 80.30 & Ref & Ref & Ref & Ref \\
\hline Yes & 787 & 598 & 75.98 & $0.88(0.79-0.96)$ & $0.007^{*}$ & $0.88(0.80-0.97)$ & $0.01^{*}$ \\
\hline
\end{tabular}


Table 3. Comparative Effectiveness of Radiation Treatment on 10- year Overall Survival by Univariate, Multivariate, and Propensity Scoree-Matched Analyses

\begin{tabular}{|c|c|c|c|c|c|c|c|c|c|c|}
\hline \multirow[t]{2}{*}{ Models } & \multirow[t]{2}{*}{ Radiotherapy } & \multirow[t]{2}{*}{ Patients } & \multicolumn{2}{|c|}{ Survival Rate ${ }^{a}$} & \multicolumn{2}{|c|}{ Univariate analysis } & \multicolumn{2}{|c|}{ Multivariate analysis ${ }^{b}$} & \multicolumn{2}{|c|}{$\begin{array}{l}\text { Propensity Score } \\
\text { Matched (n ,4962) }\end{array}$} \\
\hline & & & 5-Year (\%) & 10 -Year $(\%)$ & Log rank $\chi^{2}$ test & $P$ value & HR (95\%CI) & $P$ value & HR $(95 \% \mathrm{CI})$ & $P$ value \\
\hline \multirow[t]{2}{*}{ All patients } & No & 4296 & 59.71 & 30.56 & & & Ref & Ref & Ref & Ref \\
\hline & Yes & 2491 & 74.3 & 41.5 & 184 & $<0.001^{*}$ & $0.84(0.78-0.91)$ & $<0.001^{*}$ & $0.88(0.80-0.97)$ & $0.01^{*}$ \\
\hline \multirow[t]{2}{*}{ Hormone receptor positive } & No & 3583 & 62.27 & 31.72 & & & & & & \\
\hline & Yes & 2171 & 76.6 & 44.9 & 174 & $<0.001^{*}$ & $0.80(0.74-0.87)$ & $<0.001^{*}$ & $0.84(0.76-0.94)$ & $0.001^{*}$ \\
\hline \multirow[t]{2}{*}{ Hormone receptor negatived } & No & 713 & 46.84 & 24.73 & & & & & & \\
\hline & Yes & 310 & 50.89 & 30.97 & 7.1 & $0.008^{*}$ & $1.05(0.87-1.27)$ & 0.62 & & \\
\hline
\end{tabular}

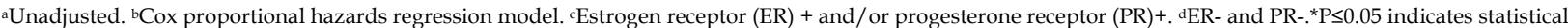
significance.

Table 4. Multivariable Analysis of Overall Survival in Matched Patients Stratified by Race.

\begin{tabular}{|c|c|c|c|c|c|c|c|c|}
\hline \multirow[t]{2}{*}{ Race } & \multirow[t]{2}{*}{ PRT } & \multirow[t]{2}{*}{ Patients } & \multicolumn{2}{|c|}{ Survival Rate } & \multicolumn{2}{|c|}{ Univariate analysis } & \multicolumn{2}{|c|}{ Multivariate analysis a } \\
\hline & & & 5-year & 10-year & Log rank $\chi^{2}$ test & $P$ value & HR (95\%CI) & $P$ value \\
\hline \multirow[t]{2}{*}{ White } & No & 1395.00 & 62.55 & 32.87 & 9.21 & 0.002 & Ref & Ref \\
\hline & Yes & 685.00 & 67.88 & 36.99 & & & $0.86(0.77-0.95)$ & 0.004 \\
\hline \multirow[t]{2}{*}{ Black } & No & 96.00 & 54.20 & 26.00 & 1.45 & 0.20 & & \\
\hline & Yes & 58.00 & 62.00 & 33.60 & & & & \\
\hline \multirow[t]{2}{*}{ Other } & No & 83.00 & 69.90 & 43.30 & 3.51 & 0.06 & & \\
\hline & Yes & 44.00 & 53.50 & 27.50 & & & & \\
\hline
\end{tabular}

${ }^{*} \mathrm{P} \leq 0.05$ indicates statistical significance. a: Adjusted for age, marital status, AJCC T, ER, PR, grade, surgery and radiotherapy for the multivariable COX analysis.
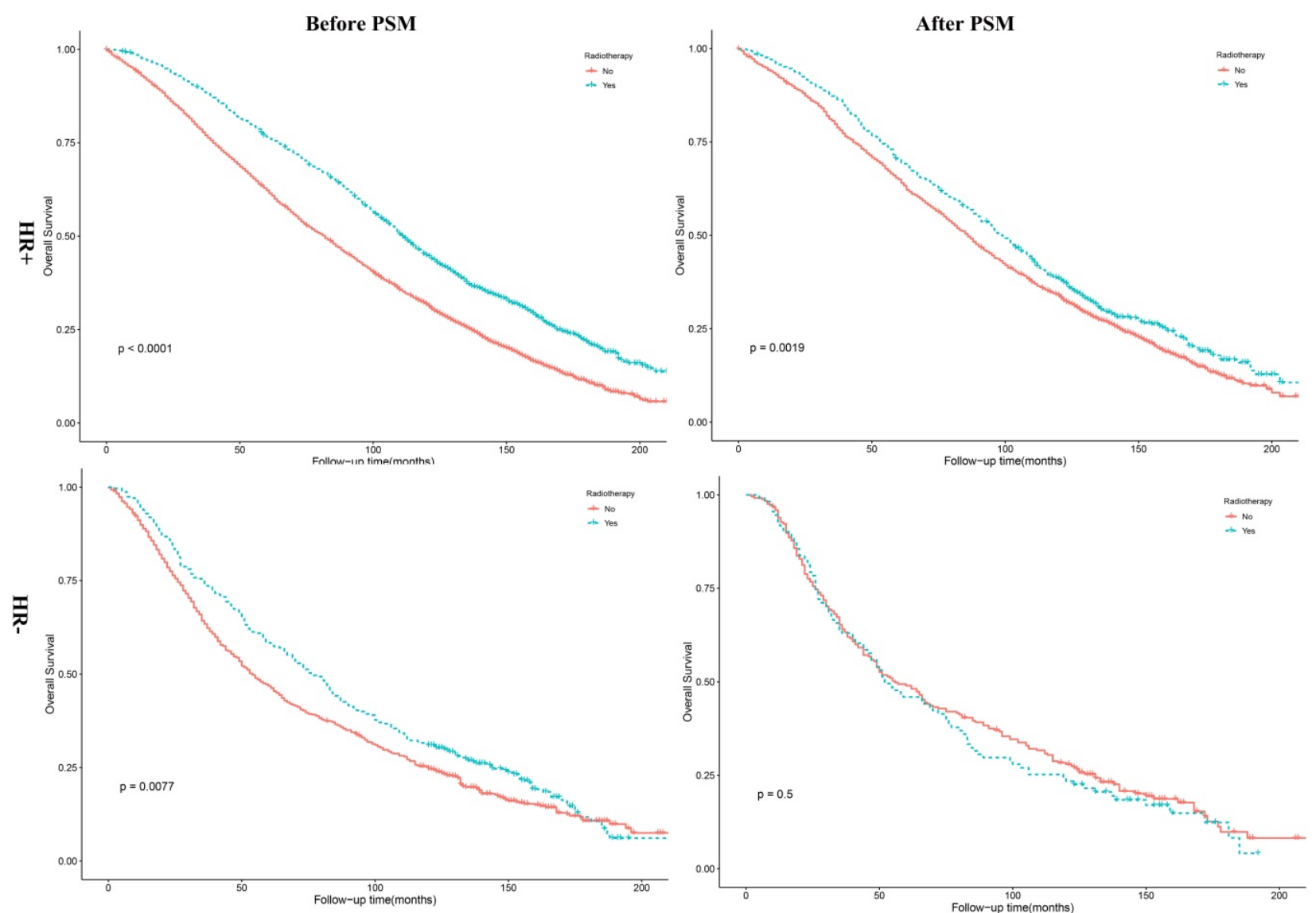

Figure 4. Kaplan-Meier survival curves for overall survival stratified by HR status before and after PSM. PSM: propensity score matching; HR+: hormone receptor positive; HR-: hormone receptor negative.

In the 13th St Gallen International Breast Cancer Conference, $64 \%$ of experts believed that PRT should not be used routinely in breast cancer patients with T1-2N1M0, but two-thirds of experts felt that PRT should be given to patients with poor prognosis [5]. A randomized trial study by Holli et al found that PRT does not increase OS in breast cancer patients [15]. Similarly, Tang et al also suggested PRT should be considered with caution for female elderly breast cancer patients [6]. However, another study 
conducted by Cosar et al found that elderly women with early breast cancer could significantly benefit from PRT [16]. The results of a trial conducted by Vaidya et al also supported targeted radiotherapy for early breast cancer [17]. The attitude towards the effect of PRT in breast cancer patients with tumor size $\leq 5 \mathrm{~cm}$ and 1-3 positive lymph nodes is still contradictory. The evidence for PRT in elderly patients is relatively weak, mainly because many clinical trials exclude women aged $\geq 70$ years-old [2]. Therefore, we conducted the study based on the SEER database to explore the role of PRT in early breast cancer.

The treatment of breast cancer depends not only on clinical pathology, but also on the breast cancer molecular subtype. Previous study revealed that molecular subtypes were also associated with radiotherapy treatment [18]. Our results showed PRT was beneficial to breast cancer patients, especially in $\mathrm{HR}+$ patients. However, we found no association between PRT and HR-patients. Compared with the number of $\mathrm{HR}+$ patients (5754 patients), the number of HR- patients (1024 patients) was relatively insufficient. Therefore, research on larger prospective clinical trials of HR-patients was still needed to verify the conclusion.

There were also some limitations to our study. First, some potential sources of heterogeneity were inevitable. For instance, we didn't know whether those patients, who didn't receive PRT, gave up all treatment and it might lead to an exaggeration of adverse prognosis without postoperative radiotherapy. Second, we found that PRT can improve patient OS but lacks data regarding the side effects of radiotherapy in patients. Third, due to the lack of data on HER2, we couldn't analyze the role of PRT in different molecular subtypes. Fourth, most patients were white in SEER database, subgroup analysis by race may lead to improper conclusions for other race. Finally, the follow-up time is best calculated after surgery and the survival time in the SEER database is calculated from the date of diagnosis.

\section{Conclusions}

Currently, there is still some controversy on whether early breast cancer patients with a tumor size $\leq 5 \mathrm{~cm}$ and 1-3 positive lymph nodes should undergo PRT. Although there are some limitations to our study, it is still strongly convincing with the advantages of large amounts of data. Our results showed that PRT was beneficial to elderly female patients with early breast cancer for OS, especially in $\mathrm{HR}+$ patients or white patients. These findings may inform future optimized options whether elderly female patients with early breast cancer should undergo postoperative radiotherapy. Research on large prospective clinical trials is still needed.

\section{Abbreviations}

PRT: postoperative radiotherapy; SEER: Surveillance, Epidemiology, and End Results; OS: Overall Survival; NCCN: National Comprehensive Cancer Network; ER: Estrogen Receptor; PR: Progesterone Receptor; PSM: propensity score matching; HR+: hormone receptor positive; HR-: hormone receptor negative.

\section{Supplementary Material}

Supplementary tables.

http://www.jcancer.org/v10p6225s1.pdf

\section{Acknowledgements}

We thank the staff at the SEER database. This study was supported by National Natural Science Foundation of China (No. 81471670); the International Cooperative Project of Shaanxi province, China (No. 2016KW-008) and the Key research and development plan, Shaanxi Province, China (2017ZDXM-SF-066).

\section{Author Contributions}

L.-H. Z. performed experiments, analyzed data and wrote the paper; performed some experiments and analyzed data; Z.-J. D. initiated the study, designed experiments. All authors read and approved the final manuscript.

\section{Ethics Statement}

This study was approved by The First Affiliated Hospital, School of Medicine, Zhejiang University. The data released from the SEER database did not require informed patient consent because cancer is a reportable disease in every state in the US.

\section{Competing Interests}

The authors have declared that no competing interest exists.

\section{References}

1. Siegel RL, Miller KD, Jemal A. Cancer Statistics, 2017. CA: a cancer journal for clinicians. 2017; 67: 7-30.

2. Kunkler I. Radiotherapy issues in elderly breast cancer patients. Breast care (Basel, Switzerland). 2012; 7: 453-9.

3. Darby S, McGale P, Correa C, Taylor C, Arriagada R, Clarke M, et al. Effect of radiotherapy after breast-conserving surgery on 10-year recurrence and 15-year breast cancer death: meta-analysis of individual patient data for 10,801 women in 17 randomised trials. Lancet (London, England). 2011; 378: 1707-16.

4. Russell NS, Kunkler IH, van Tienhoven G. Determining the indications for post mastectomy radiotherapy: moving from 20th century clinical staging to 21st century biological criteria. Annals of oncology : official journal of the European Society for Medical Oncology. 2015; 26: 1043-4.

5. Goldhirsch A, Winer EP, Coates AS, Gelber RD, Piccart-Gebhart M, Thurlimann B, et al. Personalizing the treatment of women with early breast cancer: highlights of the St Gallen International Expert Consensus on the Primary Therapy of Early Breast Cancer 2013. Annals of oncology : official journal of the European Society for Medical Oncology. 2013; 24: 2206-23. 
6. Tang L, Matsushita H, Jingu K. Controversial issues in radiotherapy after breast-conserving surgery for early breast cancer in older patients: a systematic review. Journal of radiation research. 2018; 59:789-793.

7. Yeboa DN, Evans SB. Contemporary Breast Radiotherapy and Cardiac Toxicity. Seminars in radiation oncology. 2016; 26: 71-8.

8. De Santis MC, Bonfantini F, Di Salvo F, Dispinzieri M, Mantero E, Soncini F, et al. Factors influencing acute and late toxicity in the era of adjuvant hypofractionated breast radiotherapy. Breast (Edinburgh, Scotland). 2016; 29: 90-5.

9. Williams LJ, Kunkler IH, King CC, Jack W, van der Pol M. A randomised controlled trial of post-operative radiotherapy following breast-conserving surgery in a minimum-risk population. Quality of life at 5 years in the PRIME trial. Health technology assessment (Winchester, England). 2011; 15: i-xi, 1-57.

10. Smith L, Qutob O, Watson MB, Beavis AW, Potts D, Welham KJ, et al. Proteomic identification of putative biomarkers of radiotherapy resistance: a possible role for the $26 \mathrm{~S}$ proteasome? Neoplasia (New York, NY). 2009; 11: 1194-207.

11. Cancer Genome Atlas Network. Comprehensive molecular portraits of human breast tumours. Nature. 2012; 490: 61-70.

12. Mao JH, Diest PJV, Perez-Losada J, Snijders AM. Revisiting the impact of age and molecular subtype on overall survival after radiotherapy in breast cancer patients. Scientific reports. 2017; 7: 12587.

13. Ali AA, Xiao H, Tawk R, Campbell E, Semykina A, Montero AJ, et al. Comparison of health utility weights among elderly patients receiving breast-conserving surgery plus hormonal therapy with or without radiotherapy. Current medical research and opinion. 2017; 33: 391-400.

14. Chen J, Wu X, Christos P, Yan W, Ravi A. Adjuvant Radiation Therapy for T3N0 Breast Cancer Patients Older Than 75 Years After Mastectomy: A SEER Analysis. Clinical breast cancer. 2018; 18: e967-e73.

15. Holli K, Hietanen P, Saaristo R, Huhtala H, Hakama M, Joensuu $H$. Radiotherapy after segmental resection of breast cancer with favorable prognostic features: 12-year follow-up results of a randomized trial. Journal of clinical oncology : official journal of the American Society of Clinical Oncology. 2009; 27: 927-32.

16. Cosar R, Uzal C, Tokatli F, Denizli B, Saynak M, Turan N, et al. Postmastectomy irradiation in breast in breast cancer patients with T1-2 and 1-3 positive axillary lymph nodes: is there a role for radiation therapy? Radiation oncology (London, England). 2011; 6: 28.

17. Vaidya JS, Wenz F, Tobias JS. Trial supports targeted radiotherapy for early breast cancer but protocol still requires 3 weeks of daily therapy. BMJ evidence-based medicine. 2018; 23: 38-9.

18. Pietras RJ, Poen JC, Gallardo D, Wongvipat PN, Lee HJ, Slamon DJ. Monoclonal antibody to HER-2/neureceptor modulates repair of radiation-induced DNA damage and enhances radiosensitivity of human breast cancer cells overexpressing this oncogene. Cancer research. 1999; 59: 1347-55. 